\title{
The optimal order size and the maximum shortage level decision under an order driven model
}

\author{
Peng Zhang ${ }^{1, a^{*}}$, Jie $X u^{1, b}$ \\ ${ }^{1}$ School of Economics and Management, Southeast University, Nanjing 210096, China; \\ aaaazpzp@163.com, ${ }^{b} 596897886 @ q q . c o m$ \\ *Corresponding author. Peng Zhang, aaazpzp@163.com
}

Keywords: Order driven model; Order size decision; Maximum shortage level decision; Inventory management;

\begin{abstract}
This paper mainly studies the retailer how to decision his order size and the maximum shortage level to maximize his profits. To end this, we establish an order driven model which consists of a vender and a buyer. In this model, we consider the three reality factors simultaneously: inspection errors, imperfect quality, multiple screening and shortage backordering. Based on it, we derive the optimal order size and the maximum shortage level. We also obtain three useful managerial insights. First, when the backordering cost increases, the buyer should decrease the order size and the shortage level simultaneously. Second, when freight transportation cost increases, the buyer should also increase the order size and the shortage level simultaneously. Third, the cost of accepting a defective item and the cost of rejecting a non-defective item have no impact on order size and the shortage level. Finally, we conduct numerical studies to complement our analytic findings and gain more managerial insights.
\end{abstract}

\section{Introduction}

In real life, the retailer often needs to decide how many goods order from vender and what maximum shortage level is. Therefore, many researches start to investigate this issue. The traditional economic order quantity (EOQ) model is the most commonly used for studying this issue. There are a large number of studies in this area. Based on it, some researchers further consider some reality factors, such as, inspection errors, imperfect quality, multiple screening and shortage backordering.

Hsu and Hsu (2012) [1] proposed a model in which items are delivered to customers after 100\% inspection with equally sized shipments. Tai (2013) [2] applied multiple screening processes and shortage backordering into his inventory model with no inspection errors. However, due to human errors and machine faults, defective items couldn't be fully recognized. Duffuaa and Khan (2002) [3] studied an optimal repeat inspection plan with several classifications, and an item could be divided into good, rework or scrap by considering six kinds of inspection errors. Yoo et al. (2009) [4] first consider the two inspection errors, a Type I error (classify a non-defective item to be defective) and a Type II error (classify a defective item to be non-defective). Hsu and Hsu (2013) [5] carried out a sensitivity analysis to investigate the economic impact of a Type I error and a Type II error. Ca'rdenas-Barro'n (2009) [6] developed an inventory model with planned backorders for determining the economic production quantity for a single product, in which all defective products were reworked in the same cycle. The traditional EOQ model supposes that shortage is not allowed. In fact, since defective items and inspection errors do exist, shortage may occur. Eroglu and Ozdemir (2007) [7] frist consider fully backordered of shortages. Maddah et al. (2010) [8] proposed an order overlapping scheme to prevent shortages during the screening process and the demand could be satisfied from the previous inventory. Krajewski et al. (2012) [9] propose some methods to study the optimal decision of inventory police 
under considering some reality factors. More recent literatures on inventory models can be found in Khan et al. (2011) [10].

From the above, we know that the inspection errors, imperfect quality, multiple screening and shortage backordering all have a certain impact on the retailer's decisions. To the best of our knowledge, almost all extant researches just consider one factor or two factors. This paper will consider the three factors mentioned above simultaneously. In additional, different from lots of previous academic literatures, we rework the defective items not only from the ones screened out by the buyer, but also the returned items from consumers.

\section{Model description}

We establish an order driven model which consists of a vender and a buyer. Order driven model indicates that the decision is made solely from the buyer's perspective. Then the vendor delivers products to the buyer at one time. The buyer, with a constant annual demand rate of $D$ units, places an order of $Q_{P}$. The vender satisfies the ordering by two parts. The one part is made from raw materials, $Q_{M}$. The other part is come from reworked returned items, $Q_{R}, Q_{P}=Q_{M}+Q_{R}$. The adopted raw materials for production's production rate is $P_{M}$. The adopted returned items for production's production rate is $P_{R}$. The buyer needs to pay the ordering cost $S_{V}$ per order and unit variable cost paid $c$ per unit when he orders from vender. Meanwhile, the vendor's setup cost per production run and unit production cost are $S_{V}$ and $c_{M}$. In addition, the vender also needs to pay the freight transportation cost per delivery $F$.

The vender's defective percentage is $p_{i}$. Under screening processes, the probability of a Type I error is $m_{1 i}$ and the probability of a Type II error is $m_{2 i}$. The $f\left(p_{i}\right), f\left(m_{1 i}\right)$ and $f\left(m_{2 i}\right)$ denote the probability density function of $p_{i} 、 m_{1 i}$ and $m_{2 i}$ respectively. The number of defective items found by buyer is $B_{1}$, found by consumers is $B_{2}$. Therefore, The total number of defective items is $B_{T}=B_{1}+B_{2}$. For the defective items, the vendor needs to pay unit warranty cost $v$. We use The inspector may incorrectly classify a non-defective item as defective, or a defective item as non-defective which will lead to extra cost. So we use $c_{a}$ and $c_{r}$ to denote the cost of accepting a defective item and the cost of rejecting a non-defective item respectively. We use $d_{i}$ to denote the unit screening cost.

The buyer sells a non-defective item to consumers at price $s$. The holding cost at the buyer's place is $h_{\mathbf{B}}$. Meanwhile, the holding cost for new products at vendor's place is $h_{V}$, for returned defective items is $\phi h_{V}$. Because the items may be defective, the shock-outs may happen. Therefore, the buyer needs to pay the backordering cost $b$ per unit. The maximum backordering quantity at the buyer is $B$. The Time interval between ordering and delivery is $T$. We use $T_{1}$ to denote production time intervals which products made from raw materials. And $T_{2}$ denotes Period during which the vendor supplies from inventory which comes from raw materials.

\section{Ordering and shortage level decision}

Order driven model indicates that the decision is made solely from the buyer's perspective. Then the vendor delivers products to the buyer at one time instead of $n$ delivery times. In this section, we mainly derive the optimal order size and the maximum shortage level to maximize the buyer's annual profits. To end this, we first formulates the inventory level over time both for the buyer, as shown in Fig.1. 


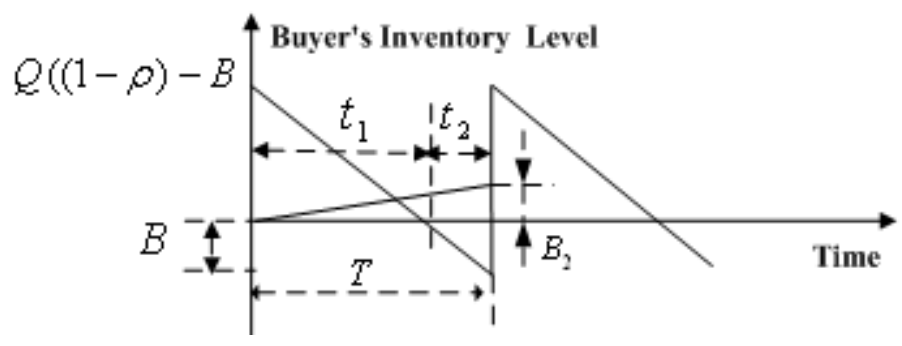

Figure. 1 Buyer's inventory over time with buyer making decisions.

Frow Fig.1, the expected annual profit per cycle for the buyer is given by

$$
\operatorname{ETPU}_{B}(Q, B)=\left\{\begin{array}{l}
-\frac{D\left(S_{B}+F+\frac{\left(b+h_{B}\right) B^{2}}{2 D}\right)}{(1-E[\rho]) Q}-\frac{h_{B}(2-2 E[\rho]-E[\alpha]+E[\rho \alpha])}{1-E[\rho]} Q \\
+\frac{D}{1-E[\rho]}\left\{\begin{array}{l}
s E[\alpha]+v(1-E[\alpha])-c_{r}(E[u]-E[\alpha]) \\
-c_{a}(1-E[\rho]-E[\alpha])-E[d]-c+\frac{h_{B} B(1-E[\rho])}{D}
\end{array}\right\}
\end{array}\right\}
$$

Where

$$
\alpha=\prod_{i=1}^{m} \alpha_{i}, u=\prod_{i=1}^{m}\left(1-p_{i}\right), \rho=\sum_{i=1}^{m} \rho_{i}, \text { and } E[d]=\sum_{i=1}^{m} d_{i}-\sum_{i=1}^{m-1}\left(E\left[\rho_{i}\right] \cdot \sum_{k=i+1}^{m} d_{k}\right)
$$

From the Eq. 1, we can get the following proposition

Proposition 1. $\operatorname{ETPU}_{B}(Q, B)$ is a jointly concave function of $(Q, B)$ and the optimal $\left(Q_{B}{ }^{*}, B_{B}{ }^{*}\right)$ have the following expressions:

$$
\begin{aligned}
Q_{B}{ }^{*} & =\sqrt{\frac{2\left(b+h_{B}\right) D\left(S_{B}+F\right)}{2\left(b+h_{B}\right) A_{1}-h_{B}{ }^{2}(1-E[\rho])^{2}}} \\
B_{B}{ }^{*} & =\frac{h_{B}(1-E[\rho])}{b+h_{B}} Q_{B}{ }^{*}
\end{aligned}
$$

Where

$$
A_{1}=h_{B}(2-2 E[\rho]-E[\alpha]+E[\rho \alpha])
$$

From proposition 1, we find that the optimal solutions, $Q_{B}{ }^{*}$ and $B_{B}{ }^{*}$ are independent of the costs of Type I and Type II errors when the decision is made solely from the buyer's perspective.

Proposition 2: When $v$ and $c$ satisfy the following inequality, the buyer's optimal expected annual profit is positive and the relationship between $v$ and care reasonable.

$$
c>v>\frac{A_{2}+\left(A_{3}+c\right) D}{D(1-E[\alpha])}
$$

Where

$$
\begin{aligned}
& A_{2}=\frac{D\left(S_{B}+F+\frac{\left(b+h_{B}\right) \cdot\left(B_{B}^{*}\right)^{2}}{2 D}\right)+h_{B}(2-2 E[\rho]-E[\alpha]+E[\rho \alpha]) \cdot\left(Q_{B}^{*}\right)^{2}}{Q_{B}{ }^{*}} \\
& A_{3}=E[d]-s E[\alpha]+c_{r}(E[u]-E[\alpha])+c_{a}(1-E[\rho]-E[\alpha])-\frac{h_{B} B_{B}^{*}(1-E[\rho])}{D} .
\end{aligned}
$$


Note that although $v$ and $c$ are exogenous variables, they have some restrictions. Since the vendor may deliver some defective items to the buyer, thus the vendor should pay warranty cost to the buyer for defective items. However, as inspection errors may occur at the buyer's place and some of the defective items may be incurred by transportation and storing, it is reasonable to set the per unit warranty cost for defective item, $v$, less than the per unit variable cost, $c$. Moreover, if we want to ensure the buyer has a positive optimal expected annual profit, $v$ should have a low boundary as shown in the above inequality.

\section{Numerical experiments}

In this section, we mainly study the sensitivity analysis. We will take one parameter at a time and keep the remaining parameters unchanged. The $p_{i} 、 m_{1 i}$ and $m_{2 i}$ follow a uniform distribution. The values of $f\left(p_{i}\right), f\left(m_{1 i}\right)$ and $f\left(m_{2 i}\right)$ are $25,16.7$ and 50 respectively. The other basic parameters are shown in following table 1 .

Table 1 Values of the basic parameters

\begin{tabular}{|l|l|l|l|l|l|l|l|}
\hline$P_{M}$ & $P_{R}$ & $D$ & $c_{M}$ & $c_{a}$ & $c_{r}$ & $c$ & $v$ \\
\hline 160000 & 200000 & 50000 & 15 & 500 & 100 & 30 & 28 \\
\hline$s$ & $b$ & $h_{B}$ & $h_{V}$ & $\phi$ & $F$ & $S_{B}$ & $S_{V}$ \\
\hline 50 & 10 & 7 & 5 & 0.6 & 25 & 100 & 300 \\
\hline
\end{tabular}

Table 2 The effects of $F$ on the optimal profits and decision variables

\begin{tabular}{|l|l|l|l|l|}
\hline$F$ & $Q_{B}^{*}$ & $B_{B}^{*}$ & $\operatorname{ETPU}_{B}\left(Q_{B}^{*}, B_{B}^{*}\right)$ & $\operatorname{ETPU}_{V}\left(Q_{B}^{*}\right)$ \\
\hline 10 & 977 & 305 & 47,214 & 759,673 \\
\hline 25 & 1,042 & 325 & 46,234 & 760,923 \\
\hline 50 & 1,141 & 356 & 44,723 & 762,572 \\
\hline 90 & 1,284 & 401 & 42,549 & 764,497 \\
\hline
\end{tabular}

As depicted in Table 2, we can see that the optimal decision variables are increasing with respect to $F$. Since both the freight transportation cost per shipment and the penalty for backordering are higher, the buyer's expected annual profit is decreasing in the order driven model.

Table 3 The effects of $b$ on the optimal profits and decision variables

\begin{tabular}{|l|l|l|l|l|}
\hline$b$ & $Q_{B}^{*}$ & $B_{B}^{*}$ & $\operatorname{ETPU}_{B}\left(Q_{B}^{*}, B_{B}^{*}\right)$ & $\operatorname{ETPU}_{V}\left(Q_{B}^{*}\right)$ \\
\hline 10 & 1,042 & 325 & 46,234 & 760,923 \\
\hline 50 & 993 & 92 & 45,454 & 759,990 \\
\hline 100 & 974 & 1 & 45,135 & 759,608 \\
\hline$\infty$ & 974 & 0 & 45,134 & 759,606 \\
\hline
\end{tabular}

Then, we study the effect of changing the backordering cost, $b$, to the optimal profits and decision variables. As shown in Table 3, we find that, with an increasing $b$, the optimal profits and decision variables have a declining tendency. When shortage is not allowed, namely $b=\infty, B=0$, the optimal solution is $Q_{B}^{*}=974$, the expected annual profit for the buyer is $\$ 45,134$, and the expected annual profit for the vendor is $\$ 759,605.94$ in the order driven model. 


\section{Conclusions}

In this paper, we mainly study the optimal order size and the maximum shortage level to maximize his profits. To end this, we establish an order driven model in which we consider the three reality factors simultaneously: inspection errors, imperfect quality, multiple screening and shortage backordering. Based on it, we then get the optimal order size and the maximum shortage level decision.

We also find three useful managerial insights. First, when the backordering cost increases, the buyer should decrease the order size and the shortage level simultaneously. Second, when freight transportation cost increases, the buyer should also increase the order size and the shortage level simultaneously. Third, the cost of accepting a defective item and the cost of rejecting a non-defective item have no impact on order size and the shortage level.

Two possible extensions of this work can be adopted. Firstly, instead of considering a certainty demand model, we next will extend the certainty demand model to an uncertainty demand model. Secondly, in real life, due to various reasons, the production rate also often changes. Therefore, we next we next will consider an inventory model with variable production rate.

\section{References}

[1] J.T. Hsu, L.F. Hsu: An integrated vendor-buyer cooperative inventory model for items with imperfect quality and shortage backordering, Advances in Decision Sciences, Vol. 2012 (2012), p.1-19.

[2] A.H. Tai: An EOQ model for imperfect quality items with multiple screening and shortage backordering, arXiv preprint arXiv:1302.1323, 2013.

[3] S.O. Duffuaa, M. Khan, An optimal repeat inspection plan with several classifications, Journal of the Operational Research Society, Vol. 2012 (2012), p. 1016-1026.

[4] S.H. Yoo, D.S. Kim, M.S. Park, Economic production quantity model with imperfect-quality items, two-way imperfect inspection and sales return, International Journal of Production Economics, Vol. 121 (2009) No.1, p.255-265.

[5] J.T. Hsu, L.F. Hsu, An EOQ model with imperfect quality items, inspection errors, shortage backordering, and sales returns, International Journal of Production Economics, Vol. 143 (2013) No.1, p.162-170.

[6] L.E. Cárdenas-Barrón, Economic production quantity with rework process at a single-stage manufacturing system with planned backorders, Computers \& Industrial Engineering, Vol. 57 (2009) No.3, p.1105-1113.

[7] A. Eroglu, G. Ozdemir, An economic order quantity model with defective items and shortages, International Journal of Production Economics, Vol. 106 (2007) No.2, p.544-549.

[8] B. Maddah, M.K. Salameh, L. Moussawi-Haidar, Order overlapping: A practical approach for preventing shortages during screening, Computers \& Industrial Engineering, Vol. 58 (2010) No.4, p. 691-695.

[9] L.J. Krajewski, L.P. Ritzman, M.K. Malhotra, Operations management (Pearson Education Limited), 2012.

[10]M. Khan, M.Y. Jaber, A.L. Guiffrida, et al., A review of the extensions of a modified EOQ model for imperfect quality items, International Journal of Production Economics, Vol. 132 (2010) No.1, p. $1-12$. 